\title{
Literatura na história e não história da literatura*
}

\section{Literature in history and non-history of literature}

\author{
Luís Bueno**
}

\begin{abstract}
RESUMO
Este artigo faz um breve relato de uma experiência de ensino de literatura em nível médio ocorrida entre 1990 e 1995 e propõe que a abordagem direta dos textos, que desloque a história literária de tema central a subsídio de leitura, seja o caminho utilizado. Somente dessa maneira o ensino médio pode formar leitores autônomos e democratizar a leitura e o acesso à literatura.

Palavras-chave: literatura brasileira, ensino de literatura, leitura.
\end{abstract}

\begin{abstract}
This paper exposes a literature teaching experience that took place in the first half of the nineties; it proposes that the student of the brazilian "ensino médio" may accomplish best results by reading the texts themselves rather than learning general information about literary history. This is the only way teachers would succeed in forming independent readers as well as help to generalize the access to literary text.

Key-words: Brazilian literature, literature teaching, reading.
\end{abstract}

* A primeira versão deste trabalho foi lida em uma mesa redonda sobre ensino de literatura, durante o XV Seminário do Centro de Estudos Literários e Lingüísticos do Paraná, realizado em outubro de 2001, em Curitiba-PR.

** Doutor em Literatura Brasileira pela Unicamp. Professor de Literatura Brasileira no DELIN/UFPR. luis.bueno@bbs2.sul.com.br 
Num de seus trabalhos, Cyana Leahy-Dios traça um interessante diagnóstico do que é o ensino de literatura no nível médio no Brasil hoje. Primeiramente, ela faz uma breve comparação do nosso caso com o caso inglês, em que o ensino não tem apoio historiográfico e se faz pela produção de ensaios pelo aluno. A conclusão a que a autora chega é a de que, independentemente das vantagens que tal método possa oferecer, ele é claramente excludente, já que pressupõe alunos "educados de berço", que tenham convívio com a literatura já em casa. Somente com esse handicap eles seriam capazes de enfrentar a primeira tarefa de seu curso de literatura, que poderia muito bem ser algo do tipo: "Escreva 5000 palavras sobre a ironia em Hamlet". ${ }^{1}$

O modelo brasileiro, por sua vez, poderia ser considerado muito mais aberto. Em princípio, não se pensa num aluno vindo da elite, já habituado a lidar com textos canônicos de nossa tradição literária. Mas, como tem acontecido com frequiência no Brasil, essa "democratização" é a socialização do precário e, se as escolas mais caras acabam se aproximando da escola pública no que diz respeito à qualidade do que se ensina de literatura, não é pela tão desejável excelência destas.

$\mathrm{Na}$ verdade, essa igualdade de condições só é possível porque há uma total e generalizada dissociação entre ensino de literatura e leitura. Do aluno do ensino médio se exige apenas a capacidade de memorizar um certo número de nomes e outras tantas características desta ou daquela época da literatura - tarefa que não exige grandes conhecimentos prévios nem maior empenho presente.

Parto desse quadro, traçado tão recentemente (o artigo mencionado foi publicado em 2000), para tratar de uma experiência que pude começar a desenvolver como professor do ensino médio há dez anos atrás, e que partiu de um diagnóstico semelhante. ${ }^{2}$ Ora, olhando àquela altura para o que em geral se fazia, e para minha própria prática, o que mais me incomodava era essa absoluta dissociação entre leitura e ensino de literatura. Qualquer livro didático que pegamos para olhar vai demonstrar claramente que, no geral, o ensino de literatura se restringe a uma equívoca coleção de

1 LEAHY-DIOS, C. Revendo os limites e possibilidades do modelo brasileiro de educação literária. Linha de Pesquisa, Rio de Janeiro, v. 1, n. 1, p. 111-123, out. 2000.

2 A experiência da qual se falará aqui foi construída em colaboração com o professor Paulo Fernando da Motta de Oliveira, que hoje ensina literatura portuguesa na Universidade Federal de Minas Gerais. 
informações de história literária em que o texto literário propriamente dito aparece como simples exemplo. O ponto de partida, então, foi esse: pensar um curso de literatura para o ensino médio que se sustentasse na leitura e não nas informações sobre estilos de época ou coisas que os valham. De maneira bem geral, é possível dizer que a idéia inicial era proceder a uma inversão desse procedimento geral, que colocasse o texto no centro da discussão da sala de aula.

Mas para poder chegar a qualquer proposta prática, era ainda preciso definir alguns elementos básicos. Um deles dizia respeito ao famoso amor à leitura. Nenhum professor de matemática ou de química ou mesmo de história se coloca a missão de transformar seus alunos em seres que amam suas disciplinas - embora, é claro, fiquem satisfeitos quando isso eventualmente acontece. Nem a sociedade tem exigido desses professores o cumprimento dessa tarefa. O professor de literatura, ao contrário, tem que ser um camarada capaz de instilar o amor à leitura. É compreensível que essa demanda apareça. Nossa sociedade dá alto valor à leitura e a considera potencialmente prazerosa - mas não gosta de ler. Então transfere para a escola a responsabilidade de fazer aquilo que é importante ficar de verdade prazeroso. Ninguém ignora que o afã de suprir essa demanda levou, muitas vezes, a um afastamento do texto. Contornou-se, muitas vezes, essa enorme dificuldade, através do recurso às histórias mais picantes, engraçadas ou comoventes que envolviam os autores e os períodos. E haja desilusão amorosa e comportamento ousado para atrair os alunos à literatura! Sem mencionar o quanto o coitado do Chico Buarque teve que ver suas músicas transformadas em exemplos vivos e extraviados de cantigas de amigo só por darem expressão a uma voz feminina.

Um outro elemento básico sobre o qual se pensou foi o seguinte: que diabos se espera que um aluno saiba de literatura ao final do ensino médio? A análise acerca da prática habitual levou a uma resposta muito desalentadora - parecida com a resposta que os adolescentes entrevistados por Cyana Leahy-Dios deram. Ora, se o que se ensina são os movimentos literários e sua relação com seu tempo histórico, o ensino de literatura não passa de um apêndice do curso de história e do curso de gramática, e sua função seria, na melhor das hipóteses, dar um verniz cultural ao aluno. Ora, se as artes foram expulsas do currículo do ensino médio, ficou na mão da literatura o pincel capaz de dar essa demão de verniz.

E o que se poderia propor acerca desses dois elementos básicos? Em relação ao primeiro, a resposta é muito simples. Promover o amor à literatura, se isso for entendido num sentido emocional, não é função do profes- 
sor e ficaria de fora de qualquer preocupação. No entanto, pode ser fator a ser levado em conta quando se pensa que gostar da literatura pode ser entendido como ter um senso desenvolvido de apreciação de textos literários. Ou seja: a capacidade de ler diferentes textos e entender suas estratégias de construção, apreciando-os pela engenhosidade dessa estratégia. No fundo, o que se fez foi a aposta de que vai gostar da literatura - independentemente de transformar a leitura numa atividade contínua sua vida afora - quem puder ler e discutir textos literários. Como é possível gostar de algo que não se conhece?

Quanto ao segundo elemento, só é possível dar uma resposta a ele se pensarmos o que seria desejável que um cidadão soubesse ao terminar o ensino médio. Em primeiro lugar, ficou claro o que ele não precisava ser. Ele não precisava ser um crítico literário. Ele não precisava ser alguém capaz de "demonstrar cultura" ao falar de autores ou escolas literárias do passado. Também era de todo secundário saber se ele estaria preparado ou não para passar nos vestibulares. A imagem que se estabeleceu foi a seguinte: o desejável é que o aluno egresso do ensino médio, não importa a que altura da sua vida, leia ou deixe de ler um determinado texto - digamos um romance - porque ele escolheu não lê-lo e não porque ele é incapaz de lê-lo. Assim, quando uma eventual adaptação televisiva de Dom Casmurro desembocasse numa nova fantástica e inevitável polêmica acerca do grande problema que é decidir se Capitu traiu ou não Bentinho, o cidadão que concluiu o ensino médio deveria ser não alguém que aprendeu na escola qual a resposta certa para essa questão; nem deveria ser alguém que já tivesse lido Dom Casmurro; nem mesmo deveria ser alguém que conhecesse outras obras de Machado de Assis. Ele deveria ser alguém que teve uma significativa experiência escolar de leitura e discussão de textos literários que o habilite a tomar o livro emprestado de uma biblioteca, lê-lo e, a partir dessa leitura e do seu repertório cultural pessoal, ser capaz de formar uma imagem pessoal do problema, de tal forma que, se alguém perguntasse a ele o que ele acha daquela polêmica, ele saberia dizer coisas como "traiu", "não traiu" ou "não sei, porque isso não tem importância para o livro" e explicar o que o levou a formar essa opinião.

Em outras palavras: o objetivo maior da presença da disciplina literatura no ensino médio é formar um leitor autônomo. Somente um leitor autônomo é capaz de ver - e usar - a literatura como instrumento efetivo de leitura do mundo ao invés de mero enfeite como ela tem a tendência de ser encarada. 
A grande pergunta que fica é a seguinte: como é que se faz para atingir esse objetivo na atual estrutura do ensino médio? Antes de mais nada é preciso esclarecer que essa experiência se deu na Escola Comunitária de Campinas, que é um colégio de classe média e tido como "alternativo". De fato, o colégio foi fundado no início dos anos 80 como uma cooperativa de pais, sendo um caso raro entre as várias experiências desse tipo, já que se manteve assim até hoje. Um caráter importante, que viabilizou o trabalho lá, é o fato de em todos os níveis a escola efetivamente acreditar que ensinar não é dar o conhecimento de bandeja ao aluno, mesmo porque isso é impossível, mas sim o de o ajudar a construir uma imagem pessoal daquele conhecimento. A idéia de "construção de conhecimento" já se tornou algo vazio, lugar-comum convertido em estratégia de marketing, que se vê até na propaganda dos colégios mais tradicionais. Mas na Comunitária não, era mais que isso. Lá, pelo menos àquela altura, havia de fato um empenho dos professores em deixar o vício arraigado de dar aulas expositivas e procurar outras estratégias que pudessem, de alguma forma, dar ao aluno a chance de fazer hipóteses e testá-las. Esse foi o grande elemento facilitador, que diferenciou este de outros colégios privados de ensino médio. $\mathrm{O}$ resto é a mesma coisa: duas aulas por semana, expectativa por parte dos pais de cumprimento de um currículo em que fosse reconhecido aquilo que habitualmente é ensinado e assim por diante.

Mas, voltando à pergunta que interessa: como formar um leitor autônomo? A primeira providência, é claro, foi abolir o uso do livro didático, já que ele está - e não conheço exceções nesse campo - comprometido com aquelas coisas todas que se queria evitar. O professor prepararia o seu próprio material de trabalho. E é aqui que a porca torce o rabo. Só é possível pensar em atividades se forem definidas antes as linhas mestras do que vai ser o trabalho durante os três anos do ensino médio. Podemos dizer que duas linhas mestras se definiram:

1- A linha histórica da literatura brasileira e da literatura portuguesa que faz parte do currículo do ensino médio em São Paulo - seria levemente modificada. $\mathrm{O}$ estudo da narrativa seria feito autonomamente em relação ao estudo do texto poético. Um problema prático banal originou essa decisão. Uma abordagem rigorosamente cronológica de ensino das literaturas brasileira e portuguesa faz com que a leitura de narrativas longas, penso aqui especificamente no romance, só possa ser iniciado lá pelo meio do segundo ano. E pareceu claro que era preciso um investimento de tempo maior do que um ano e meio para que fosse possível tentar formar um leitor autôno- 
mo de romances, já que um romance exige um tempo mais extenso de leitura. Para dar um exemplo, a estrutura curricular do primeiro ano ficava, então, a seguinte:

a) Leitura e discussão de um texto do teatro clássico, preparada pela leitura de trechos da Poética, de Aristóteles.

b) Leitura e discussão de um trecho de alguma novela de cavalaria medieval.

c) Leitura e discussão de algum texto narrativo do Renascimento eu gostava de trabalhar especialmente com o Macbeth.

d) Leitura e discussão de uma série de romances do século XIX, franceses (em tradução), portugueses e brasileiros, que a escola chamaria de textos românticos, mas que na prática de sala de aula não eram identificados senão como textos publicados neste ou naquele ano.

e) Simultaneamente a essa leitura dos romances do século XIX, nos intervalos em que se estava lendo, iniciava-se o trabalho com o texto poético, a partir da lírica medieval portuguesa.

f) Leitura de texto teórico sobre o Romantismo que encerrava o curso. Somente aí vários alunos percebiam que aquilo que eles aprendiam tinha alguma coisa a ver com o que os amigos que estudavam em outros colégios estudavam. Isso ocupava não mais que uma aula de 50 minutos no final do ano.

Esse procedimento, de abordagem simultânea da ficção e da poesia, era mantido até o terceiro ano.

2- Em hipótese alguma a abordagem de o que quer que fosse, no curso de literatura, começaria com a palavra do professor sobre a questão. Ao professor caberia, é claro, dirigir a discussão, mas jamais caberia a ele dizer algo como "o que vamos ver hoje é exemplar disso ou daquilo". Assim, num determinado dia, os alunos recebiam um papel que continha alguns poemas e algumas questões sobre esses poemas. A aula inteira era usada para a leitura dos poemas, a reflexão sobre os problemas colocados nas questões e a redação de uma resposta. O professor, nesse dia, corria de um lado para o outro, tentando resolver dúvidas pontuais, ajudar numa discussão feita entre dois colegas e assim por diante. Na aula seguinte, seria a vez de discutir as respostas dadas às questões. Processo semelhante era utilizado na abordagem dos romances. Era marcada uma 
data para uma prova a respeito de um determinado livro, e essa prova seria a primeira abordagem ao livro feita na sala de aula. Nenhuma aula sobre o livro, sobre o autor ou sobre o período literário era dada antes daquele momento. Na prova, o aluno contava apenas com sua leitura para dar conta dos problemas que as questões colocavam para ele. $\mathrm{Na}$ aula posterior, as questões - assim como algumas respostas efetivamente dadas nas provas - eram discutidas. Era a partir dos problemas levantados na prática da análise, portanto, que era construída uma discussão sobre os textos literários.

Fica claro que, numa sistemática como esta, a avaliação é vista como elemento interno ao processo de ensino e não como uma verificação final dos conhecimentos adquiridos. As questões de uma prova retomavam problemas discutidos em provas anteriores ou levantados em discussões feitas em sala, de tal forma que as provas eram constantes - pelo menos uma a cada duas semanas - e o resultado atípico de um aluno numa avaliação tinha a tendência de ser diluído no seu resultado final, mesmo porque a escola trabalhava com faixas de notas, expressas em conceitos, e não com valores numéricos.

É claro que literatura, nessa escola, deixou de ser uma matéria considerada fácil. Alguns alunos a consideravam efetivamente difícil. E eu gostaria de lembrar que lidar com o texto - literário ou não - não é mesmo tarefa fácil, de resultados seguros. As notas obtidas no início do primeiro ano seriam mesmo consideradas ruins por pessoas que olham as notas como simples resultado de alguma coisa. Basta dizer que a porcentagem de "notas vermelhas" em literatura só era menor (e discretamente menor) do que a de matemática. Mas, à medida que o curso ia se desenvolvendo, esse contingente ia diminuindo, embora jamais cessasse de vez. Literatura virou, naquele contexto, uma disciplina como outra qualquer, em que havia possibilidade de ir bem ou mal, ao contrário do que usualmente era visto uma matéria "fácil", segundo os adolescentes entrevistados por Cyana LeahyDios.

Essa experiência, que se encerrou no ano letivo de 1995 - os professores que me sucederam não se interessaram em prossegui-la -, parece permitir chegar a duas conclusões que, no fundo, são mesmo propostas.

1- Um curso médio de literatura pensado sobre um eixo histórico não precisa necessariamente dissociar leitura e ensino de literatura. Principalmente se a história literária se constituir exatamente nisso: um eixo, ao invés de uma estrutura fechada. Assim se, ao invés de as escolas públicas 
receberem milhões de exemplares de livros didáticos que trazem uma pobre visão da história da literatura brasileira, recebessem milhões de exemplares de livros que contenham textos de literatura brasileira, a história literária poderia ser reduzida ao papel auxiliar de organização das leituras. Não vejo razão para desprezarmos uma tradição enorme de abordagem histórica da literatura na escola, na qual se formou praticamente todo e qualquer professor secundário em atividade hoje. Não é possível empreender qualquer tentativa de melhoria do ensino de literatura em nível médio no Brasil, aqui e agora, ignorando essa tradição, que não é essencialmente redutora, apenas acidentalmente o tem sido.

2- É preciso tomar cuidado para não cair, no ensino médio, na mesma esparrela em que caiu a leitura no ensino fundamental. A invasão da dita literatura infantil não produziu qualquer ganho significativo. O que se vê em prática nas escolas é a leitura de livros produzidos a partir de uma visão estereotipada de leitura, de escola e de infância pautada pela necessidade de agradar ao aluno. O resultado é que o aluno lê com prazer um livro, que muitas vezes reproduz modelos da literatura comercial mais estandardizada (pense-se na estória policial), depois lê outro semelhante, com semelhante prazer. Mas, quando ele chega ao ensino médio, não suporta ler. Por que será que isto acontece? É claro que há um conjunto de fatores extremamente complexo a ser levado em consideração. Mas não tenho dúvidas de que o prazer mais imediato da leitura - aquele encontrado ao ver revelado o assassino ao final da trama, por exemplo - seja incapaz de agregar a leitura à vida das pessoas. Mais incapaz é ainda de contribuir para formar leitores autônomos. Ora, educar é procurar ajudar alguém a andar onde nunca esteve antes. A repetição de fórmulas narrativas é exatamente o contrário disso. Lembremos que um video-game perde a graça quando chegamos ao fim. $\mathrm{O}$ interessante é exatamente ter que vencer mais um desafio.

É exatamente por isso que penso que os textos canônicos têm papel importante a cumprir no ensino de literatura do ensino médio. Mesmo que não seja por suas características internas, e sim pela longa tradição de leituras que fazemos deles, esses textos têm agregada em si uma complexidade da qual o professor pode sempre tirar partido. Ler um texto produzido em condições muito diversas daquelas do presente do leitor, escrito numa linguagem diferente daquela a que o leitor habitualmente tem acesso é sempre um exercício que envolve um certo grau de dificuldade - e tem potencial para ser tarefa intelectual desafiadora. 
Não quero dizer com isso que somente os textos ditos canônicos têm esse potencial - e, apesar de estar defendendo aqui o cânone, acho perfeitamente possível que um curso de literatura seja excelente sem nem sequer passar pela leitura de autores como Machado de Assis ou Guimarães Rosa - desde, é claro, que ele passe por uma diversidade de textos, que remetam a uma diversidade de questões. Mesmo porque a democratização do saber literário que eu imagino passa necessariamente pelo acesso a esses textos. Somente se conhecidos eles podem ser dessacralizados.

Neste passo, gostaria de fazer uma analogia com o ensino de língua materna. Quando o professor Paulo Freire assumiu a secretaria de educação do município de São Paulo, na gestão de Luiza Erundina, deu interessante entrevista em que afirmava que as escolas públicas do município ensinariam ao aluno que a sua forma de falar era válida, eficaz e bela. No entanto, também ensinaria que havia uma modalidade, dita culta, que seria cobrada dele socialmente. Aprendê-la era essencial para sua constituição como cidadão. Mas aprendê-la não era abandonar sua forma de falar, e sim entender a necessidade de identificar as situações em que ela não era adequada, e poder se valer de uma forma de falar mais próxima da norma:

Precisamos respeitar a sintaxe [dos meninos] mostrando que sua linguagem é bonita e gostosa, às vezes é mais bonita que a minha. E, mostrando tudo isso, dizer a ele: "Mas para tua própria vida tu precisas dizer 'a gente chegou' [e não 'a gente cheguemos']. Isso é diferente, é diferente. É assim que queremos trabalhar, com abertura, mas dizendo a verdade". ${ }^{3}$

Em duas palavras: o fim do preconceito lingüístico não depende da destruição da norma culta, mas da percepção de que há diferentes papéis sociais possíveis e de que também há diferentes registros lingüísticos, mais ou menos compatíveis com os tais papéis sociais.

Questionar a existência de um "valor intrínseco" às obras que compõem o cânone literário me parece atitude, mais do que válida, necessária. Tão necessária como questionar o "valor intrínseco" da norma culta. Mas é preciso considerar que vivemos numa sociedade em que o cânone ainda tem valor - e mais uma vez apelo ao artigo de Cyana Leahy-Dios, em que se transcrevem trechos de entrevistas com os alunos do ensino médio: no

3 Entrevista publicada pela Folha de São Paulo, em 08 dez. 1988. 
primeiro ano, antes de serem expostos à máquina de moer cérebro do ensino de literatura, eles vêem uma importância na literatura que seus colegas de terceiro ano não enxergam mais.

Estamos, de um lado, no fundo do poço da democracia do precário; por outro lado, o ensino médio, a esta altura da vida nacional, de um jeito ou de outro, se populariza de forma nunca vista. Será que não é exatamente esta a hora de, pelo menos nesse campo, quando temos a nosso lado a arma oficial do currículo escolar, mostrar efetivamente que a leitura de João Cabral de Melo Neto ou Gregório de Matos ou José de Alencar ou Cecília Meireles vale não porque transforma os iniciados que a fazem em seres refinados e superiores, mas sim porque aponta para elementos da nossa cultura que contribuem para ver o mundo de uma forma um pouquinho diferente, mais matizada? Não seria essa uma forma de efetivamente transformar o ensino de literatura num veículo de democratização cultural num país em que todo tipo de democracia - a econômica, a racial, a política parece impossível?

\section{REFERÊNCIA}

LEAHY-DIOS, C. Revendo os limites e possibilidades do modelo brasileiro de educação literária. Linha de Pesquisa, Rio de Janeiro, v. 1, n. 1, p. 111-123, out. 2000.

Texto recebido em 22 jul. 2002

Texto aprovado em 26 ago. 2002 